\title{
Ceramide Is Responsible for the Failure of Compensatory Nerve Sprouting in Apolipoprotein E Knock-Out Mice
}

\author{
Dusica Maysinger, ${ }^{1}$ Michael Holmes, ${ }^{2}$ Xianlin Han, ${ }^{4}$ Richard M. Epand, ${ }^{3}$ Evi Pertens, ${ }^{2}$ Anne Foerster, ${ }^{2}$ Cia Barlas, ${ }^{2}$ \\ David M. Holtzman, ${ }^{5}$ and Jack Diamond ${ }^{2}$ \\ ${ }^{1}$ Department of Pharmacology and Therapeutics, McGill University, Montreal, Quebec, Canada HG3 1Y6, Departments of ${ }^{2}$ Psychiatry and Behavioural \\ Neurosciences and ${ }^{3}$ Biochemistry, McMaster University, Hamilton, Ontario, Canada L8N 3Z5, and Departments of ${ }^{4}$ Medicine and ${ }^{5}$ Neurology, Washington \\ University School of Medicine, St. Louis, Missouri 63110
}

\begin{abstract}
Apolipoprotein $\mathrm{E}(\mathrm{apoE})$ is a key transporter of the cholesterol and phospholipids required for membrane synthesis and nerve growth. We now report a virtual absence in apoE knock-out (KO) mice of normal nerve growth factor (NGF)-driven compensatory sprouting of undamaged cutaneous nociceptive nerves. In contrast, NGF-independent regeneration of crushed axons was unaffected. Essentially similar results came from aged wild-type mice. In apoE KO mice, the endogenous sprouting stimulus was suspect, because NGF administration induced normal sprouting; nevertheless, NGF increased normally in denervated skin, transported normally in the axons, and led to phosphorylation of trkA, erk1, and erk2. However, sprouting was restored in apoE K0 mice (although not in aged mice) by fumonisin $\mathrm{B} 1$, an inhibitor of ceramide synthesis. A shotgun analysis revealed a wide array of changes in individual ceramide species in DRG neurons of apoE KO mice, and the changes for ceramide species $\mathrm{OH} \_\mathrm{N} 15: 0$ made it a candidate inhibitor of sprouting (increased in apoE K0 mice and normalized by fumonisin B1). Nevertheless, the unknown effects of individual ceramide species on sprouting, as well as the variability of their changed levels in apoE KO mice and how these were affected by fumonisin B1, support a different conclusion. We suggest that absence of apoE expression alters the balance among ceramide species to one that collectively inhibits compensatory sprouting, whereas fumonisin B1 establishes a new balance that allows sprouting. Nontoxic ceramide modulators might usefully promote sprouting and circuitry repair in neurodegenerative disorders in which ceramide species are perturbed, adding to the benefits of reducing ceramideinduced neuronal apoptosis.
\end{abstract}

Key words: nerve sprouting; axonal regeneration; ceramide; apoE; aging; Alzheimer's disease; cutaneous nerve; NGF; nerve growth factor

\section{Introduction}

Collateral sprouting of axons, often called "compensatory sprouting," is an important self-repair mechanism in the nervous system (Diamond, 1982; Gage et al., 1983; Diamond et al., 1992a; Szot et al., 2006). Sprouting is adversely affected by aging (Scheff et al., 1978; Crutcher, 2002) and by the apolipoprotein E4 (apoE4) isoform of apoE, the major apolipoprotein in the nervous system (Nathan et al., 1994; Holtzman et al., 1995), making impaired sprouting a likely contributor to the neurological risk presented by these two conditions. This risk, identified initially for Alzheimer's disease (Poirier et al., 1993; Strittmatter et al., 1993), now extends to multiple disorders of the CNS and PNS (Bedlack et al., 2000; Desrosiers et al., 2005; Mahley et al., 2006). An impairment of the role of apoE in sprouting could be common to apoE KO mice, aged mice and humans, and conceivably to apoE4-expressing humans and mice. ApoE levels are reduced

\footnotetext{
Received June 4, 2007; revised June 5, 2008; accepted June 17, 2008.

This work was supported by Ontario Neurotrauma Foundation, Canadian Institutes of Health Research, and the Alzheimer's Association.

Correspondence should be addressed to Jack Diamond, Department of Psychiatry and Behavioural Neurosciences, McMaster University, 1200 Main Street West, Hamilton, Ontario, Canada L8N 375. E-mail: diamond@mcmaster.ca.

DOI:10.1523/JNEUROSCI.1461-08.2008

Copyright $\odot 2008$ Society for Neuroscience $\quad$ 0270-6474/08/287891-09\$15.00/0
}

in aged brains (Lahiri, 2004), whereas in apoE knock-out (KO) mice there is reduced sprouting of both CNS neurons (Masliah et al., 1996; Champagne et al., 2005) and dorsal root ganglia (DRG) neurons in vitro (Handelmann et al., 1992). The role of apoE in sprouting was discovered over two decades ago by Shooter and colleagues (Skene and Shooter, 1983; Ignatius et al., 1986, 1987) working with peripheral neurons and PC12 cells, and later was extended to neurons of the CNS (Poirier, 1994; Masliah et al., 1996). In summary, apoE derived from glia and Schwann cells and, after peripheral nerve injury, from invading macrophages, forms complexes with cholesterol and phospholipids released from damaged neurons, and then delivers these to the same or neighboring neurons to be used for membrane synthesis and new nerve growth.

There have been some anomalous findings in apoE KO mice, however, including a persistence of normal central sprouting (Anderson et al., 1998) and regeneration of peripheral myelinated axons (Popko et al., 1993). The present study used a well characterized peripheral nerve growth paradigm (Diamond et al., 1992a,b; Lourenssen et al., 2000) to identify growth impairments attributable to absence of apoE functions in apoE KO mice. We also looked for obvious abnormalities in a few selected relevant signaling pathways, although such pathways were not the focus of the study. As a comparator, selected growth parameters were 
examined in aged wild-type mice. In both animal models, axonal regeneration was normal, but nociceptive sprouting was absent. Given the role of NGF in the latter but not the former (Diamond et al., 1992a,b), a defect in NGF functions seemed likely, and in the aged animals the sprouting defect was indeed attributable to a reduced responsiveness to NGF. In marked contrast, the failure to sprout in apoE KO mice turned out to be caused by an inhibitory action of neuronal ceramide, although the possibility that ceramide metabolites might be implicated was not excluded. Overall, the findings suggest a basis for therapies that might promote reparative nerve growth in neurodegenerative disorders.

\section{Materials and Methods}

Animals

Breeding pairs of homozygous transgenic mice lacking the apoE gene (strain B6.129P2-Apoe ${ }^{\text {tmlUnc } / J ; ~ s t o c k ~ n u m b e r ~ 002052) ~ w e r e ~ o b t a i n e d ~}$ from The Jackson Laboratory. Information from The Jackson Laboratory indicates that the appropriate controls for these apoE KO mice are C57BL/6 mice. Wild-type (C57BL/6) mice were obtained from Charles River Laboratories. Mice were housed in cages with microisolators and had access to food and water ad libitum.

\section{Animal studies}

All of the animal procedures used in these studies were approved by the Animal Research Ethics Board of McMaster University and conformed to the Canadian Council on Animal Care guidelines. Operative procedures and the electrophysiological mapping of "light-touch" nerve fields were performed under deep surgical anesthesia (sodium pentobarbitone, $60 \mathrm{mg} / \mathrm{kg}$, administered intraperitoneally). Mapping of nociceptive fields was done during maintained administration of sodium pentobarbitone (45 mg/kg), which allowed cutaneus trunci muscle (CTM) reflex responses (see below) to be elicited while maintaining the anesthetic state. At the termination of all experiments, animals were killed while under deep surgical anesthesia.

\section{"Isolation" and mapping of sensory nerve fields}

The techniques used to map cutaneous nerve territories (sensory fields), and to measure their reestablishment by collateral sprouting or regeneration after denervation of skin (see below), were essentially the same as previously described for rats (Diamond et al., 1992a,b) and mice (Lourenssen et al., 2000). The segmental nerves which supply the back skin were exposed by a para midline incision, and the nerve field to be studied [that of the dorsal cutaneus nerve (DCN) at the T12 level, DCN-T12] was then "isolated" on one side; this was done by excising the four DCNs rostral and four caudal to it, and the lateral cutaneus nerves supplying the adjacent ventral flank skin. These denervations resulted in the isolation of the back skin region innervated by the DCN-T12 of one side within a vast surround of totally denervated skin. After skin repair and recovery, the mechano-nociceptive field (subserved by A $\delta$ fibers) and the heatnociceptive field (subserved by $\mathrm{C}$ fibers) of the innervated territory were mapped in the anesthetized mouse by systematic application across the skin of a fine forceps pinch or a briefly applied $60^{\circ} \mathrm{C}$ heat probe, respectively. In innervated skin, these nociceptive stimuli evoke the reflex contraction of the underlying cutaneus trunci muscle which causes a visible twitching of the skin (the CTM reflex). The border between the innervated skin region and the denervated (reflexly unresponsive) skin was marked with a fine fiber-tipped pen, and the mapped areas traced onto transparent acetate sheets for measurement.

\section{Collateral sprouting}

The progress of collateral sprouting was followed by repeating the mapping procedure periodically over the $22 \mathrm{~d}$ after field isolation to determine the expansion of the responsive areas. It was shown in the previous rat studies that these nociceptive field expansions correlate quantitatively with the progressive reinnervation of the surrounding initially denervated skin by axons sprouting outwards from the still-innervated island, or (as described below) by axons regenerating to the skin along a degenerating peripheral nerve pathway.

\section{Axonal regeneration}

After the sensory nerve isolation and initial field area measurements described above, the nerve was crushed with fine forceps for two $10 \mathrm{~s}$ periods, midway between the point of nerve exit from the body wall and entry into the skin. The completeness of the crush was confirmed by the disappearance of the CTM reflex response. The nerve then regenerated to, and reinnervated, the now totally denervated skin. The progress of reinnervation by nociceptive fibers was monitored by periodic mapping of the nociceptive field areas as described above for collateral sprouting. In these regeneration studies, however, the large $A \beta$ fibers that subserve the low-threshold (light-touch) fields were also able to be examined electrophysiologically, because although, when undamaged, they fail to undergo collateral sprouting in skin, they regenerate normally after nerve crush (Yasargil et al., 1988). The touch fields were mapped by stroking the skin with a fine bristle, which evoked impulses that were recorded from the DCN-T13 by bipolar platinum electrodes attached to a preamplifier, a storage oscilloscope, and an audio amplifier. As the bristle crossed the border between innervated and denervated skin, the impulse bursts disappeared abruptly. The mapped areas were traced and measured as described above for the nociceptive fields.

\section{Axon counts}

Selected DCNs were excised, placed into $2.5 \%$ glutaraldehyde fixative, postfixed with osmium tetroxide, dehydrated in an acetone series, and embedded in Spurr's resin. Subsequently, 90-nm-thick sections were cut and placed on Formvar-coated slot grids for electron microscopic (EM) examination. The MCID image analysis system (Imaging Systems) was used to measure the axonal areas (myelin excluded) and myelin thickness for random samples of axons. Myelin thickness was used as a critical aid to distinguishing $\mathrm{A} \delta$ and $\mathrm{A} \beta$ fibers in normal nerves (in regenerating nerves, all myelinated axons were counted as a single group); fibers with myelin thickness $>0.3 \mu \mathrm{m}$ were classified as $\mathrm{A} \beta$, and fibers with a thickness $\leq 0.3 \mu \mathrm{m}$ were classified as $\mathrm{A} \delta$. Variability in myelin thickness around a single axon was dealt with by taking the average of four measurements in different regions of a given axon profile.

\section{Preparation and characterization of NGF and its antiserum}

The preparation and purification of nerve growth factor $(2.5 \mathrm{~S}$ NGF or $7 \mathrm{~S}$ NGF) from male mouse salivary glands of anti-NGF antiserum (antiNGF) from adult sheep and the evaluation of potency in functional assays were performed as described in detail by Diamond et al. (1992a,b), Gloster and Diamond (1992), and Mearow et al. (1993). ELISAs have shown that our polyclonal antibody recognizes NT-3, although to a significantly lesser extent than NGF and, to an even lesser extent, BDNF (Murphy et al., 1993), but in in vitro survival assays it blocks only the biological activity of NGF and not that of NT-3 and BDNF (R. Kolbeck and Y.-A. Barde, personal communication). In preliminary in vitro mouse dorsal root ganglia studies, our anti-NGF had a small effect on sprouting induced by NT-3, whereas BDNF-induced sprouting was unaffected (Van der Zee et al., 1995). We must allow, therefore, for the possibility that our antibodies could interfere with a possible endogenous NT-3-induced sprouting of a subpopulation of DRG neurons reported to coexpress trkA and trkC (Karchewski et al., 1999).

\section{Administration of NGF and of anti-NGF antiserum}

NGF (2.5S) was dissolved in an acetate vehicle, $\mathrm{pH}$ 6.4, and injected intraperitoneally daily for $19 \mathrm{~d}(1 \mu \mathrm{g} / \mathrm{g}$ body, i.p.). Subcutaneous injections of anti-NGF were made daily in the groin region (anatomically remote from the dorsal cutaneus nerves and the back skin they innervated).

\section{Measurement of NGF protein levels in skin and retrogradely transported along nerves}

The tissues examined were innervated and denervated skin. Retrograde axoplasmic transport was measured by nerve ligation technique, an accepted approach that has become standard in the field (Johnson et al., 1987; Raivich and Kreutzberg, 1987; Bhattacharyya et al., 2002). Two millimeter nerve segments were taken immediately distal to ligatures (a thin strand unraveled from a $4 / 0$ braided silk thread) that had been placed around the nerves $18 \mathrm{~h}$ earlier; each animal provided five nerve 

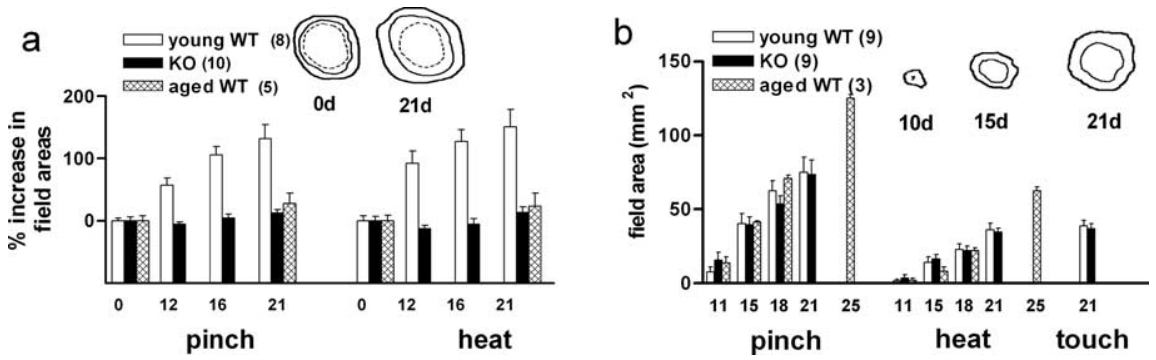

Figure 1. Collateral sprouting into adjacent denervated skin fails in apoE KO mice and in aged mice, but axonal regeneration occurs normally. $\boldsymbol{a}$, Sprouting of mechano-nociceptive (pinch) and heat-nociceptive (heat) fibers in DCN-T13, $21 \mathrm{~d}$ after isolation of the nerve field by denervation of surrounding skin was measured as percentage increase, final field area relative to initial field area. The animal groups studied were young adult ( $2-3$ months) and aged ( 18 months) wild-type (C57BL/6) mice (WT) and young adult apoE KO mice. Aged mice were measured only initially and at $21 \mathrm{~d}$ after isolation. The inset sketches show typical fields (not to scale) at 0 and $21 \mathrm{~d}$; the innermost (dashed) outline is that of the low-threshold mechano-sensitive ("touch") fibers, which do not undergo collateral sprouting. The intermediate outline is the field of the heat-nociceptive fibers, and the outermost one the field of the pinch (mechanical)-nociceptive fibers. The extent of sprouting at $21 \mathrm{~d}$ was assessed using ANOVA $\left(F_{(2,20)}=19.55\right)$. There was significant nociceptive nerve sprouting in the young adult WT group $(p<0.0047)$, but not in the aged WT and the apoE $K 0$ groups. $\boldsymbol{b}$, Axonal regeneration was measured by the restoration and progressive expansion of the two nociceptive and the touch field areas after their disappearance after nerve crush. The first measurements were made at $11 \mathrm{~d}$ after nerve crush for the nociceptive fibers and at $21 \mathrm{~d}$ (the only measurement) for the touch fibers. In the aged mice, the last nociceptive field measurements were made at $25 \mathrm{~d}$ and not at $21 \mathrm{~d}$. Regeneration rates of both nociceptive fiber types were not significantly different (ANOVA; $F_{(2.25)}=0.578 ; p>0.56$ ) for the three animal groups (young adult WT, aged WT, and apoE K0), nor was regeneration of touch fibers at $21 \mathrm{~d}$ significantly different in young adult WT mice and in apoE KO mice. The inset sketches show typical young adult WT nociceptive fields (not to scale) at 10, 15, and $21 \mathrm{~d}$; the outer perimeter is the pinch field, and the inner is the heat. At $21 \mathrm{~d}$, the touch field coincided with the heat field. In aged WT mice, touch fiber regeneration occurred but was not studied quantitatively. In this and subsequent figures, the numbers above histograms and alongside inset legends show numbers of animals used. Error bars indicate SEM.

Table 1. Fiber populations in DCN-T12

\begin{tabular}{lllr}
\hline & A $\beta$ fibers & A $\delta$ fibers & \multicolumn{1}{c}{ C fibers } \\
\hline WT & $118.8 \pm 10.18$ & $120.0 \pm 9.8$ & $961.5 \pm 109.2$ \\
apoE KO & $108.5 \pm 6.1$ & $120.8 \pm 7.4$ & $1110.0 \pm 146.3$
\end{tabular}

No significant differences were found between fiber types in wild-type (WT) and KO mice (Mann-Whitney U test).

Table 2. Axonal regeneration in DCN-T12 distal to a crush made $35 \mathrm{~d}$ earlier

\begin{tabular}{llc}
\hline & A fibers (\%) & C fibers (\%) \\
\hline WT & 88.5 & 93.9 \\
apoE KO & 96.1 & 100.6 \\
\hline
\end{tabular}

Unmyelinated and myelinated fiber populations ( $A \beta$ and $A \delta$ fibers combined) in distal nerve segments are presented as a percentage of the corresponding populations above the crush. No significant differences were found between wild-type (WT) and K0 nerves ( $p>0.02$, ANOVA).

samples, from DCNs T11-L2 on one side. Tissues were collected onto dry ice and stored at $-70^{\circ} \mathrm{C}$ until assay. The material was homogenized in lysis buffer (137 mm NaCl, $20 \mathrm{~mm}$ Tris, 1\% NP-40, 10\% glycerol, $1 \mathrm{~mm}$ PMSF, $10 \mu \mathrm{g} / \mathrm{ml}$ aprotinin, $1 \mu \mathrm{g} / \mathrm{ml}$ leupeptin). This homogenate was centrifuged at $13,000 \times g$ for $30 \mathrm{~min}$ and the resulting supernatant was frozen at $-70^{\circ} \mathrm{C}$ and thawed for use as necessary. NGF protein was measured using the NGF $E_{\max }$ Immunoassay System (Promega) according to the manufacturer's instructions. The total protein content of all supernatant samples was determined using the BCA assay (Pierce) according to the manufacturer's directions. For each of the samples that are assayed by ELISA, NGF protein levels were calculated as picograms of NGF per microgram of total protein.

\section{Immunoprecipitation and Western blot analyses}

Materials. Novex SDS-PAGE 4-20\% gels and 10× Novex Tris-glycine SDS running buffer were purchased from Invitrogen; Blue Ranger molecular weight marker was purchased from Pierce; and Trans-Blot nitrocellulose membrane was purchased from Bio-Rad. The following antibodies were used: rabbit anti-trkA, rabbit anti-erk, and rabbit antiphospho-erk from Cell Signaling; mouse anti-phosphotyrosine from Millipore; and sheep anti-mouse-HRP and donkey anti-rabbit-HRP from GE Healthcare. Polyclonal antibody against p75 was kindly provided by Dr. P. Barker (Montreal Neurological Institute, Montreal, Quebec, Canada).

In the exogenous NGF studies, the trkA and mitogen-activated protein (MAP) kinase measurements were made $20 \mathrm{~min}$ after a single NGF injection, and in the endogenous NGF ones were made $2 \mathrm{~d}$ after skin denervation, when its NGF content reaches levels adequate to induce nerve sprouting in adjacent skin (Diamond et al., 1992a,b; Gloster and Diamond, 1992; Mearow et al., 1993).

Protein extraction and immunoprecipitation. DRGs and dorsal cutaneous nerves, the latter excised from close to the skin to their entry into the body wall $(\sim 2.5 \mathrm{~cm})$, were stored until extraction at $-80^{\circ} \mathrm{C}$. The tissues were incubated in lysis buffer $[100 \mu \mathrm{l} ; 50 \mathrm{~mm}$ Tris-HCl, $\mathrm{pH}$ 8.0, $1.37 \mathrm{~mm} \mathrm{NaCl}, 1 \%(\mathrm{v} / \mathrm{v})$ Nonidet P-40, 10\% $(\mathrm{v} / \mathrm{v})$ glycerol, $0.1 \mathrm{~mm}$ sodium orthovanadate, and complete protease inhibitor mixture tablet (Roche Diagnostics)] for $20 \mathrm{~min}$ on ice. They were homogenized with a glass homogenizer (Duall 20; Kontes Glass) on ice. The samples were centrifuged, and the supernatants $(40 \mu \mathrm{l})$ were separated and boiled with $6 \times$ sample buffer. The protein concentrations were determined by Bio-Rad Protein Assay using BSA as a standard. The remaining lysates $(60 \mu \mathrm{l})$ were used for immunoprecipitations with anti-trkA $(1 \mu \mathrm{g} / \mu \mathrm{l})$. Immunoprecipitated trkA proteins were then separated by incubation with agarose beads ( $50 \mu$ l of beads/ sample; $2 \mathrm{~h}$ at $4^{\circ} \mathrm{C}$ ), the supernatant was discarded, and the beads were washed five times with lysis buffer and dissolved in $6 \times$ sample buffer $(30$ $\mu \mathrm{l})$. The samples were stored at $-20^{\circ} \mathrm{C}$.

Immunoblotting. The denatured samples were run on a $4-20 \%$ SDSPAGE. The proteins were transferred to a nitrocellulose membrane and blocked with blocking buffer ( $1 \%$ chicken albumin plus $1 \%$ BSA in TBS+T) overnight at $4^{\circ} \mathrm{C}$. Membranes were incubated with primary antibodies [trkA or phosphotyrosine (1:1000); phospho-erk1/2 (1:5000)] or p75 (1:1000) in blocking buffer for $48 \mathrm{~h}$ at $4^{\circ} \mathrm{C}$. Membranes were subsequently incubated with the secondary antibody (HRP-labeled anti-rabbit or anti-mouse; $1: 7500$ ) in 5\% nonfat dry milk for $1 \mathrm{~h}$ at room temperature. Finally, membranes were washed with TBS $+\mathrm{T}$ (three times for 15 min each time) and exposed to Lumi-GLO (Cell Signaling). Films (Kodak X-OMAT Blue XB-1) were developed using Kodak X-OMAT 2000A Processor, and fluorescent signals were evaluated by densitometry [scanned with UMAX Astra 2000P scanner, using Presto! PageManager version 4.20.02 (New Soft); semiquantified using Scion Image version $\beta-3 \mathrm{~b}$ (Scion Corporation)]. Differences in signal intensities (from a minimum $n=4-5$ ) were considered significant at $p<0.05$.

\section{Ceramide measurements}

Mice DRGs and DCNs were homogenized in $1 \mathrm{ml}$ of ice-cold $\mathrm{LiCl}$ aqueous solution $(50 \mathrm{~mm})$ with a Potter-Elvehjem tissue grinder. Protein assays on each individual homogenate were performed. A homogenate $(\sim 1 \mathrm{ml})$ from each DRG sample was transferred to a disposable culture borosilicate glass tube $(16 \times 100 \mathrm{~mm})$, an internal standard [i.e., C17:0 Ceramide (300 pmol/mg protein)] was added to each tube and lipids extracted by a modified Bligh and Dyer procedure as described previously (Cheng et al., 2006). Each lipid extract was resuspended in $100 \mu \mathrm{l}$ of $\mathrm{CHCl}_{3} / \mathrm{MeOH}(1: 1 ; \mathrm{v} / \mathrm{v})$. The lipid extracts were finally flushed with nitrogen, capped, and stored at $-20^{\circ} \mathrm{C}$ for electrospray ionization/mass spectrometry (MS) analyses (typically within 1 week). Each lipid solution was diluted $\sim 50$-fold immediately before infusion and lipid analysis at a flow rate of $4 \mu \mathrm{l} / \mathrm{min}$ with a syringe pump. Mass spectrometric analyses of ceramide molecular species were performed as previously described 
(Han, 2002). Typically, a 5 min period of signal averaging in the profile mode was used for each tandem MS analysis.

\section{Results}

Collateral sprouting is absent in both apoE $\mathrm{KO}$ mice and aged mice

In young adult wild-type mice, within 1-2 weeks after "isolating" the innervation field of a single DCN by eliminating neighboring nerves, its mechano-nociceptive and heat-nociceptive skin territories ("fields") begin to expand into the surrounding denervated skin (Fig. $1 a$, inset). These expansions are attributable to collateral sprouting of the small myelinated $(\mathrm{A} \delta)$ and unmyelinated $(\mathrm{C})$ nociceptive fibers, respectively, in the isolated nerve (Diamond et al., 1992a,b; Lourenssen et al., 2000). The key finding in the present study was a near-total absence of nociceptive field expansions in both apoE $\mathrm{KO}$ mice and in aged wild-type mice over the extensive period examined (Fig. 1a). Because of a previous report of $\mathrm{C}$ fiber reductions in sciatic nerves of apoE $\mathrm{KO}$ mice (Fullerton et al., 1998), reductions that might somehow relate to an impaired sprouting of surviving fibers, we made an EM examination of DCNs in these animals. These nerves were found to contain quantitatively and morphologically normal populations of large and small myelinated fibers and of unmyelinated fibers ( $\mathrm{Ta}$ ble 1).

\section{Axonal regeneration occurred normally in apoE $\mathrm{KO}$ and aged mice \\ ApoE KO mice}

We extended the EM studies to nerves that were regenerating after a crush injury, and confirmed quantitatively the earlier lightmicroscopic reports (Popko et al., 1993) of normal myelinated axonal regeneration within distal nerve trunks of apoE $\mathrm{KO}$ mice. The EM findings showed too that regeneration of the unmyelinated fibers also occurred normally downstream to the crush site in these animals (Table 2). Behavioral and electrophysiological approaches allowed a functional examination of the continued growth of sensory nerves within the skin. The results showed that, in apoE KO mice, the regeneration of the fibers subserving all three sensory modalities studied occurred normally, as evidenced by the progressive reestablishment of the "pinch" fields of the small myelinated mechano-nociceptive nerves, of the "heat fields" of the unmyelinated heat-nociceptive nerves, and of the "light-touch fields" of the large myelinated low-threshold mechanosensory $\mathrm{A} \beta$ fibers (Fig. $1 b$ ). The last group of fibers regenerate but do not undergo compensatory collateral sprouting in adult rodent skin (Yasargil et al., 1988).

Aged wild-type mice

A parallel study was performed in normal aged mice. The results showed that, in these animals too, the functional regeneration of b

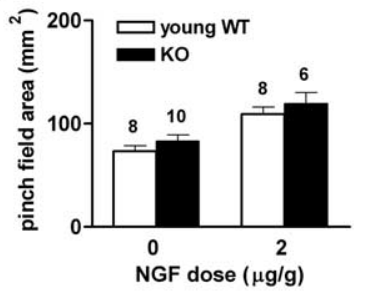

C

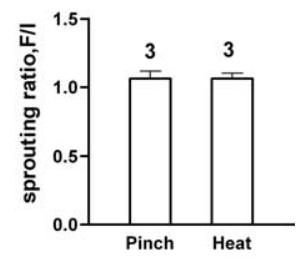

Figure 2. $\quad \boldsymbol{a}$, NGF induced sprouting in apoE K0 mice. Sprouting was measured by the progressive expansion of DCN-T13 pinch fields in mice after their isolation. Expansions are indicated on the ordinate as the "sprouting ratios" (the isolated field areas measured at " $F$," the later specified time, relative to the initial field areas, I, measured immediately after the isolation procedure, and normalized to 1.0; the ratio value 1 equals absence of sprouting). In this and subsequent figures, WT are wild-type mice, and and continued daily for $19 \mathrm{~d}$. By $21 \mathrm{~d}$, no significant sprouting had occurred in the untreated apoE KO mice, but NGF treatment WT mice. The data were analyzed using one-way ANOVA, with Bonferroni's multiple comparison test to show where significances reside (overall, $p<0.0001$; ANOVA; $F_{(3,28)}=16.48$ ). The untreated apoE KO results are significantly different from any of the different from each other $(p>0.05)$. In a number of places, the SE bars are concealed within the symbols used in these graphs. , NGF induces sprouting in unoperated mice. Daily NGF injections for 19 d into unoperated mice resulted in an expansion of pinch immediately after completion of the $19 \mathrm{~d}$ injection protocol. There was no significant difference in the field expansions between DoEKO and WT mice. (ANOVA; $\left.F_{(3,42)}=1.143 ; p<0.0006\right)$. c, NGF fails to evoke sprouting in aged animals. Daily administration fibers. This is indicated as in $\boldsymbol{a}$ by the sprouting ratios; here the isolated field areas were measured only initially and at $20 \mathrm{~d}$ after

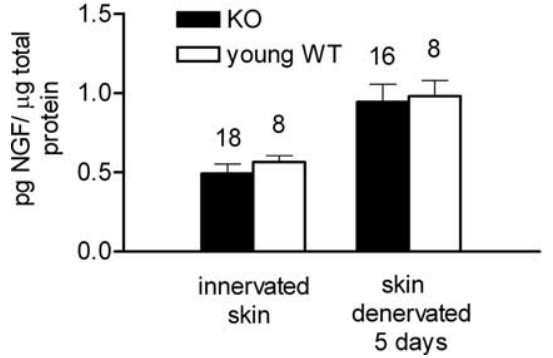

Figure 3. No differences in cutaneous NGF levels or in retrograde NGF transport in WT and apoE KO mice. $\boldsymbol{a}$, NGF levels in normally innervated skin of young adult WT mice were not significantly different from those in apoE KO mice ( $p>0.447)$, nor was there a significant difference between the (increased) NGF levels in the skin of apoE KO and WT mice $5 \mathrm{~d}$ after their denervation NGF accumulation in pooled $2 \mathrm{~mm}$ nerve segments distal to a ligature that had been secured around the nerves $18 \mathrm{~h}$ earlier. The nerves used were $\mathrm{T} 10-\mathrm{T} 13$ and L1-L3 from both sides. There was no significant difference in NGF content between apoE K0 and young adult WT mice at zero time (i.e., before ligation) $(p>0.27)$ or at $18 \mathrm{~h}$ after ligation ( $p>0.77$ ) (Mann-Whitney's $U$ test). Error bars indicate SEM.

both classes of nociceptive nerves, triggered by nerve crush, occurred normally, restoring the normal nociceptive fields in the skin (Fig. 1b). Although not examined quantitatively, light-touch responsivity, subserved by the mechanosensory $\mathrm{A} \beta$ fibers, also returned to the previously denervated skin in aged animals (data not illustrated).

\section{Impaired responsiveness to NGF explains the sprouting defect in aged mice but not in apoE $\mathrm{KO}$ mice}

Given the key role of endogenous NGF in nociceptive nerve sprouting but not in axonal regeneration (Diamond et al., $1992 a, b)$, the preceding results pointed to an apparent defect in NGF functions in both apoE KO and aged mice. We examined this possibility by administering NGF exogenously. The results were dramatically different for the two animal types. 


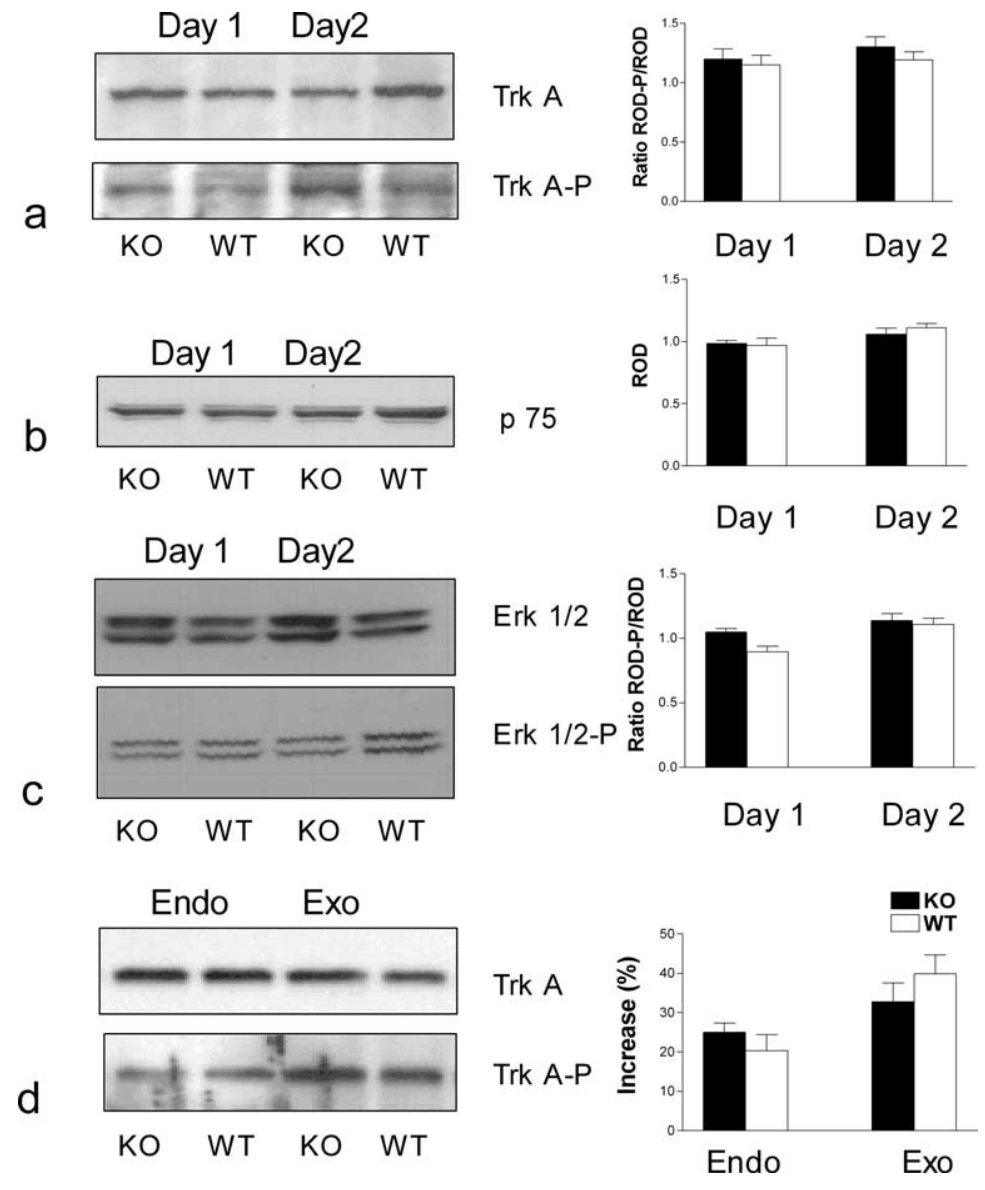

Figure 4. $\boldsymbol{a}-\boldsymbol{c}$, trkA, p75 receptor, and ERK1/2 expression are comparable in WT and apoE KO mice. Expression and phosphorylation of NGF receptors and ERK1/2 were measured in five young adult wild-type and five apoE KO mouse DCNs taken on either day 1 or day 2 after denervation of adjacent skin. Twelve to 16 nerves were excised from each animal, and each set was pooled separately. The nerves were lysed and separated using gradient gels 4-20\% SDS-PAGE as described in Materials and Methods (representative gels are shown in the left panels). Immunoreactive bands were revealed by using primary antibodies. $\boldsymbol{a}$, trkA or phospho-trkA (1:1000). $\boldsymbol{b}$, p75 (1:1000). c, Erk 1/2 or phospho-Erk1/2 (1:5000). $\boldsymbol{d}$, Exogenous NGF induced more trk phosphorylation than endogenous NGF. Twenty minutes after a single injection of NGF $(1 \mu \mathrm{g} / \mathrm{g})$ to both WT and apoE KO mice, trk phosphorylation (Exo) was significantly greater $(p<0.05)$ than that measured on the second day of the sprouting paradigm (Endo) for both animal groups [NGF content in denervated skin reaches levels adequate to induce nerve sprouting in adjacent skin after $2 \mathrm{~d}$ (Diamond et al., 1992a,b; Gloster and Diamond, 1992; Mearow et al., 1993)]. In $\boldsymbol{a}-\boldsymbol{d}$, immunoreactive bands were analyzed with MCID-Elite 6 analysis software (Imaging Research) and SYSTAT 9 statistical software (SPSS). Values are expressed as means \pm SEM of the ratios of relative optical densities (RODs) for phosphorylated/nonphosphorylated proteins (trk and erk1/2) and the mean ROD for 775 expression, for day 1 and day 2 after initiation of sprouting (bar graphs on the right). Differences were considered not significant $(p>0.05)$.

ApoE KO mice

After isolation of the selected nerve field, daily injections of NGF now elicited sprouting into the adjacent denervated skin of apoE $\mathrm{KO}$ mice to an extent not significantly different $(p>0.09)$ from that of the normal denervation-induced sprouting in young adult wild-type mice (Fig. 2a). However, NGF injections did not increase the sprouting in the wild-type mice (Fig. 2a), suggesting that the endogenous NGF levels in their denervated skin (Fig. 3a) had increased to levels that saturated the sprouting response. NGF injections into apoE KO mice may have been approaching comparable saturation levels (Fig. 2a). Systemic NGF injections also induced sprouting within the normally innervated skin of unoperated apoE KO mice just as in that of the control unoperated young adult wild-type animals (Fig. $2 b$ ).

Aged control mice

NGF injections that induced sprouting in the apoE KO mice were also made daily for $19 \mathrm{~d}$ after the (ineffective) field isolations in aged control animals. In contrast to the apoE KO results, these injections failed to elicit sprouting (Fig. 2c).

\section{Are endogenous NGF functions impaired in apoE $\mathrm{KO}$ mice?}

Because sprouting was evoked in these animals by injected NGF but not by the assumed endogenous NGF stimulus in adjacent denervated skin, we focused our investigations on the anticipated impairments of endogenous NGF-related functions. We found none.

First, NGF protein levels in innervated apoE KO mouse skin were normal, and they increased normally after skin denervation (Fig. 3a).

Second, axonal transport of NGF occurred normally from innervated skin, and increased normally in nerves adjacent to denervated skin (Fig. $3 b$ ).

Third, the expression in the DCNs of p75, and both the expression and phosphorylation of trkA, were comparable in apoE KO and wild-type mice (Fig. $4 a, b$ ), but in some paired specimens there was a trend, which failed to reach significance, of an increased expression of $\mathrm{p} 75$ in apoE $\mathrm{KO}$ DCNs (data not shown). After denervation of adjacent skin, the intensity of both unphosphorylated and phosphorylated trkA signals were not significantly different in the DCNs of the two animal genotypes (Fig. 4a) or in their DRGs (neuronal somata and glial cells) (data not shown).

Fourth, expression and phosphorylation of erk1 and erk2, relevant trkAdependent downstream MAP kinases, were comparable in DCNs of apoE KO and wild-type mice (Fig. 4c). In both apoE KO and wild-type mice, exogenous NGF activated trkA in the DRG more effectively than endogenous NGF (Fig. $4 d$ ).

\section{Ceramide is responsible for the} defective sprouting in apoE KO mice but not that in aged mice The following studies were triggered by a previous report showing that a ceramide analog inhibited outgrowth from neonatal sympathetic neurons in vitro when it was applied to the axons but not when it was applied to the cell bodies (de Chaves et al., 1997).

\section{Fumonisin studies on sprouting}

Fumonisin B1 is an inhibitor of endogenous ceramide synthesis (Desai et al., 2002; Merrill et al., 1993). We first examined whether administration of fumonisin B1 $\left(1 \mu \mathrm{g} \cdot \mathrm{g}^{-1} \cdot \mathrm{d}^{-1}\right.$ in $0.9 \% \mathrm{NaCl}$, s.c.) would affect the absence of sprouting in apoE $\mathrm{KO}$ and in aged wild-type mice. In the former, the treatment essentially restored sprouting to normal levels (Fig. 5a). The recovered sprouting was blocked by anti-NGF administration, proving that it represented the normal sprouting response to the endogenous NGF stimulus (Fig. $5 a$ ). In aged wild-type mice, absence of sprouting persisted despite fumonisin B1 administration 
(Fig. 5b). Consequently, the remaining studies focused on the apoE KO mice, specifically on the possibility that increased ceramide levels in their neurons would explain the inhibition of their sprouting.

\section{Total ceramide levels}

These have already been studied in mouse DRGs and found to be $25-30 \%$ higher in apoE $\mathrm{KO}$ mice than in wild-type mice (Cheng et al., 2007). Because of the differential effects of $\mathrm{C}(6)$-ceramide on nerve and cell bodies in the in vitro studies mentioned above (de Chaves et al., 1997), we extended the ceramide studies to the DCNs. The total concentrations in the DCNs were found to be on average $\sim 2$ - to 2.5-fold higher than in the DRGs, but surprisingly, there were no significant differences between the DCNs of apoE KO and wild-type mice. We turned, therefore, to an examination of individual ceramide species.

\section{Individual ceramide species}

Shotgun lipodomic analyses (Cheng et al., 2007; Piomelli et al., 2007) were performed on DRGs and DCNs collected $3 \mathrm{~d}$ after initiating the sprouting paradigm. One group of animals received fumonisin B1 treatment $\left(1 \mu \mathrm{g} \cdot \mathrm{g}^{-1} \cdot \mathrm{d}^{-1}\right.$ in $0.9 \% \mathrm{NaCl}$, s.c. $)$ on each of the $3 \mathrm{~d}$. The results were extremely variable (supplemental Table 1, available at www.jneurosci.org as supplemental material). Some individual ceramide species concentrations increased in the DRGs and/or the DCNs of apoE KO mice relative to wildtype values (OH_N16:0, OH_N15:0, N24:1, OH_N15:0), whereas others decreased (N:16, N18:1, N22:1). Fumonisin B1 also gave variable results; in the DRGs of both wild-type and apoE $\mathrm{KO}$ mice, most species concentrations were increased (N22:1, N22:0, N24:0, N24:1, N24:2), but one (OH_N15:0) was decreased, whereas in the DCNs only the concentrations of N16 and OH_N15:0 were reduced. Four examples of these findings are graphed in Figure 6, for N:16:1, N18:1, N24:1, and OH_N15:0. The full set of data is provided in supplemental Table 1 (available at www.jneurosci.org as supplemental material).

We interpret this somewhat bewildering array of results as implying that it is the balance among ceramide species that is critical to whether or not sprouting occurs, and this is discussed below. It is interesting, however, that one ceramide species $\left(\mathrm{OH} \_\mathrm{N} 15: 0\right)$ (Fig. 6) matched our expectation of an increased concentration in apoE KO mouse neurons that was significantly reduced by fumonisin $\mathrm{B} 1$.

\section{Discussion \\ Different mechanisms underlie the impaired sprouting in apoE KO and aged mice}

Denervated rodent skin regions normally become reinnervated by compensatory sprouting from nociceptive and sympathetic fibers supplying adjacent skin that is driven by the increased NGF in the deprived skin (Diamond et al., 1992a,b; Gloster and Diamond, 1992; Mearow et al., 1993). Remarkably, compensatory sprouting of nociceptive nerves was absent in both the apoE KO mice and the aged wild-type mice, yet the same axons regenerated normally after nerve crush. Given that NGF is critical only for sprouting and not for regeneration (Diamond et al., 1992a,b; Gloster and Diamond, 1992; Mearow et al., 1993), it seemed ini- b

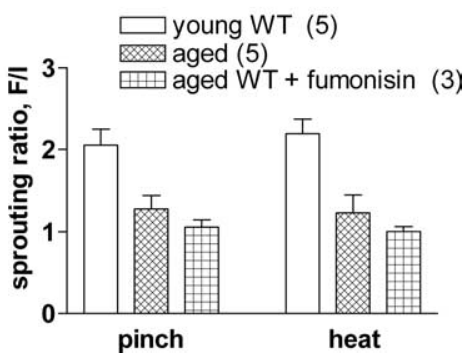

tially that defective NGF-based functions would be implicated. In the aged mice, this was indeed the case, with injected NGF failing entirely to evoke a sprouting response. The surprising findings came from the apoE KO mouse studies.

First, injected NGF evoked sprouting just as in wild-type mice, the sprouting into denervated skin exceeding that within innervated skin (Fig. $2 a, b$ ), presumably because of competition with the resident nerve endings in the latter. Second, although it was ineffective, NGF increased normally in denervated skin of apoE $\mathrm{KO}$ mice and was retrogradely transported along the cutaneous axons in normally increased amounts, and finally, p75, and phosphorylated trkA, erk 1 and erk 2, were consistently detected. We concluded that, in the apoE KO mice, endogenous but not exogenous NGF-driven sprouting is inhibited by some endogenous molecules in the target tissue. The likeliest candidates turned out to be ceramides.

Newly synthesized ceramide inhibits endogenous NGF-driven nociceptive sprouting in apoE KO mice

Ceramides, integral elements of cell membranes, and also lipid second messengers, have been studied particularly in the context of neuronal apoptosis (de Chaves et al., 2001; Hannun and Obeid, 2008). In the light of a previous report that C (6)ceramide (a water soluble analog of naturally occurring ceramides) inhibited axonal outgrowth from newborn sympathetic neurons in vitro (de Chaves et al., 1997), we examined whether endogenous ceramide could be responsible for the sprouting defect in apoE KO mice. The results supported this: fumonisin B1, which inhibits ceramide synthesis through the salvage pathway (Desai et al., 2002; Kitatani et al., 2008), an effect also demonstrated in neurons (Merrill et al., 1993), quantitatively restored the sprouting; this was blocked by anti-NGF treatment and thus represented the normal NGF-driven growth. However, simple information on total ceramide content did not satisfactorily explain these findings (total ceramide in the DCNs did not differ between control and apoE KO mice, for example). More illuminating results came from shotgun lipidomics (Han, 2002; Cheng et al., 2007; Piomelli et al., 2007), which allow for detection of different lipid species in minute amounts of tissue.

The results represent the first attempt to correlate changes in individual ceramide species concentrations in a whole-animal 

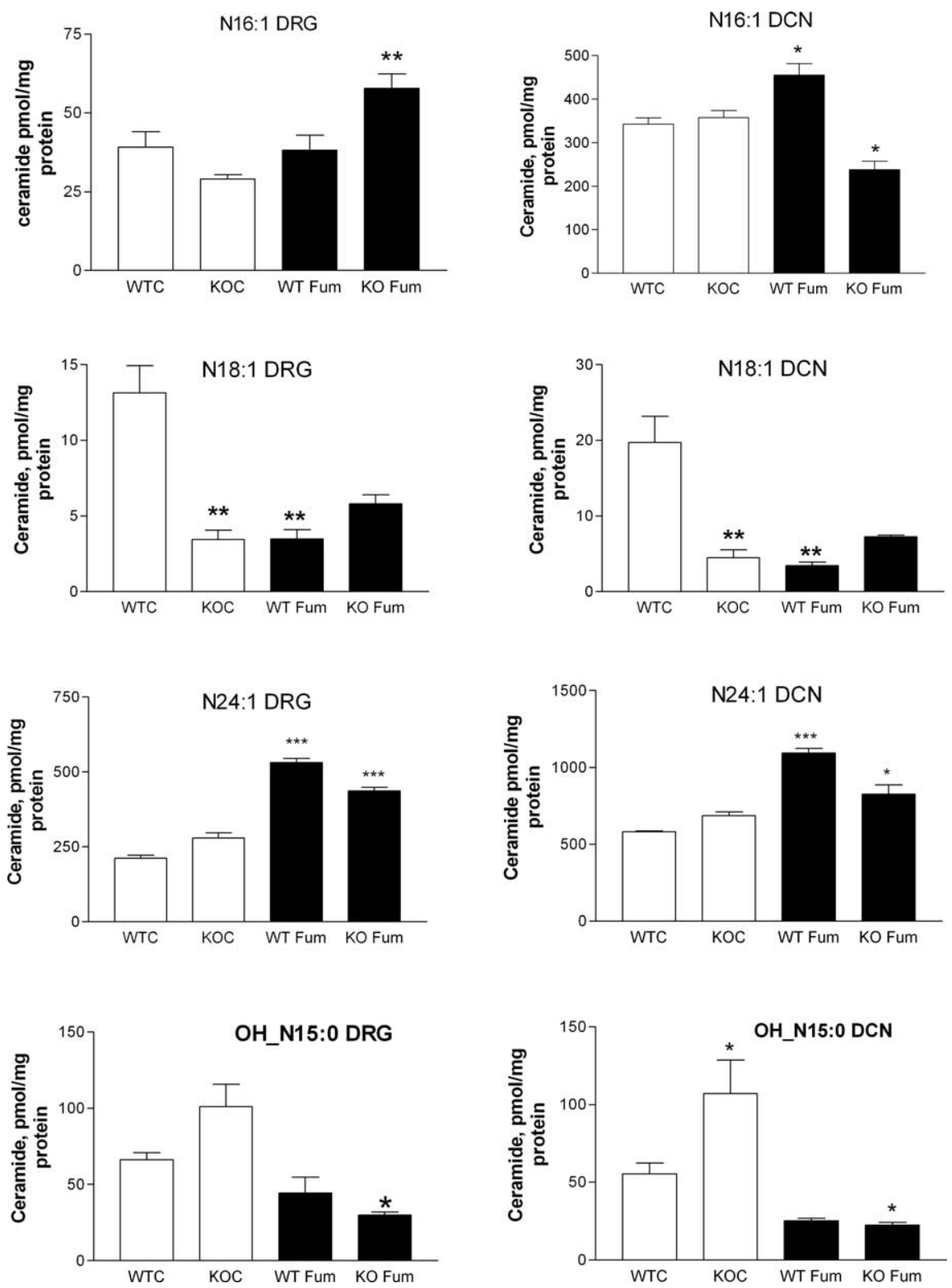

Figure 6. Concentrations of various ceramide species in DRG (left side of each pair) and DCN (right side of each pair) in untreated and fumonisin B1-treated wild-type and apoE KO mice. The species identities are (pairs, from top to bottom) N16:1, N18:1, N24:1, and OH_N15:0. WTC are wild-type mice, KOC are apoE K0 mice, WT Fum are wild-type mice treated with fumonisin B1, and KO Fum are apoE KO mice treated with fumonisin B1. The data in each graph were analyzed using ANOVA, with Bonferroni's multiple comparison tests, as follows: WTC versus KOC, WTC versus WT Fum, and KOC versus KO Fum. Significant differences are $^{*} p<0.05,{ }^{* *} p<0.01$, and ${ }^{* * *} p<0.001$. Thus, where KOC (open) columns are starred, this refers to comparison with the corresponding WTC (open) columns, and where fumonisin-treated (black) columns are starred, this is relative to the corresponding untreated column. The data for ceramide species examined are provided in supplemental Table 1 (available at www. jneurosci.org as supplemental material). Error bars indicate SEM.

model with changes in nerve growth. The findings for one ceramide species (OH_N15:0) actually matched our initial expectations that one or more ceramide species would change significantly in the DCNs of apoE KO mice, and that these changes would be significantly reduced by fumonisin B1. We now revise this point of view: first, some ceramide species can promote nerve growth (Riebelin and Futerman, 2002); second, as we now show, absence of apoE expression results in increases in some individual species, but decreases or no change in others, and third, these species changes can be enhanced, or reduced, or remain unaffected, by a fumonisin B1 treatment that restores sprouting (the full set of data is provided in supplemental Table 1, available at www.jneurosci.org as supplemental material). We conclude that it is the balance achieved among the entire population of individual ceramide species and their compartmentalization (Hannun and Obeid, 2008) that determines what impact there will be on sprouting. In wild-type animals, the balance is supportive; in apoE $\mathrm{KO}$ animals, it is nonsupportive or actively inhibitory; and in apoE $\mathrm{KO}$ animals treated with fumonisin $\mathrm{B} 1$, a supportive balance is attained in which newly synthesized fumonisin B1-sensitive ceramide species are implicated (Kitatani et al., 2008). This view does not disallow possible adverse effects in apoE KO mice of other lipid-related changes (Cheng et al., 2007).

In a few studies on apoE KO mice exposed to the sprouting paradigm, we observed a trend in an increased p75 expression in DCNs (data not shown), which if confirmed as significant might also implicate this receptor in impaired sprouting. A continued NGF stimulation of p75 in neural cultures leads to increasing intracellular ceramide concentrations, and to both increases and reductions in neuritogenesis (Riebelin and Futerman, 2002; Blöchl and Blöchl, 2007).

\section{Why did the ceramide changes fail to} affect crush-induced axonal regeneration and exogenous NGFinduced sprouting?

One possibility is that these growth stimuli are simply more powerful than that provided by endogenous NGF. It is interesting that arriving regenerating nerves readily displace recently established sprouted ones whose growth and maintenance is NGF dependent (Diamond, 1982). Moreover injected NGF induced more trkA phosphorylation in the DRGs of both wild-type and apoE KO animals than did endogenous NGF. Relevant too is the observation that NGF may be more effective when applied to cell bodies than to nerve terminals (Toma et al., 1997). There is another possibility, however. In the original in vitro study (de Chaves et al., 1997), ceramide inhibited NGF-initiated growth when it was applied to distal axons, but not when it was applied to the cell bodies. In the present studies, the endogenous NGF in skin targets the cutaneous nerve terminals buried in the blood-vessel-free epidermis (Pertens et al., 1999), but injected NGF can be assumed to more readily access the neuronal cell bodies and proximal axons. The cell body is also generally assumed to be where the axotomy-induced regeneration stimulus acts (Kanje et al., 1991). Thus, in the present studies, axonal ceramide might have counteracted the local effects of distally acting endogenous NGF while failing to inhibit the effects on the cell body of axotomy or injected NGF. 
Given the key role of apoE in nerve growth, the substantial restoration of sprouting in apoE $\mathrm{KO}$ mice by fumonisin $\mathrm{B} 1$ seems somewhat paradoxical. The likeliest explanation is that there is redundancy in the mechanisms involved, with other apolipoproteins substituting for apoE (Popko et al., 1993; Anderson et al., 1998).

\section{How could ceramide inhibit sprouting in apoE KO mice?}

One plausible explanation is that synthesized ceramide (fumoni$\sin$ B-sensitive) activates the serine/threonine protein phosphatases (PP1) of the cell (Chalfant et al., 1999), leading to enhanced dephosphorylation of glycogen synthase kinase 3 (GSK3 $\beta$ ), a prominent downstream target of PI3K (phosphatidylinositol 3-kinase); in its nonphosphorylated form, GSK3 $\beta$ inhibits NGFinduced nerve growth (Arévalo and Chao, 2005). The explanations discussed above could then account for the failure of the ceramide to inhibit growth induced by exogenous NGF and axotomy. PP1 also dephosphorylates specific isoforms of protein kinase C (PKC) (Kitatani et al., 2007), which are implicated in neurite outgrowth in the PNS (Tsai et al., 2007); their dephosphorylation would inhibit neurite outgrowth by interfering with subcellular compartmentalization of PKC/PKA (protein kinase A).

Finally, the effects of ceramide on sprouting could also come about, at least in part, through the modulation by ceramide of the local concentration, distribution, and dynamics of growthrelated membrane proteins/receptors in lipid rafts (Chiantia et al., 2006, 2008; Johnston and Johnston, 2006, 2008).

\section{Do the present findings help explain the neurological threats of aging and of apoE4 expression?}

In general, collateral sprouting has the same characteristics in the CNS and PNS, although this is not so for axonal regeneration, which is not normally a feature of the mammalian CNS. If indeed the present findings do apply to central neurons, they might well be relevant to the impairment of central sprouting in aging (Scheff et al., 1978; Crutcher, 2002) and with apoE4 expression (Nathan et al., 1994; Holtzman et al., 1995; White et al., 2001), defects that very likely contribute to the neurological risks of these two influences (Poirier et al., 1993; Strittmatter et al., 1993; Bedlack et al., 2000; Desrosiers et al., 2005; Mahley et al., 2006). Our findings provide a striking example of the well documented reduced effectiveness of growth factors in aged nervous systems (Bergman et al., 1999; Crutcher, 2002), a phenomenon we did not explore further in this study. In contrast, the sprouting defect in the apoE $\mathrm{KO}$ animals was consistent with its being attributable to an overall rebalancing among the individual ceramide species, although a specific inhibitory action of the ceramide species OH_N15:0 is also possible. Ceramide increases occur in aged and in Alzheimer brains (Cutler et al., 2004a; Crivello et al., 2005; Han, 2005), but a correlation between ceramide and apoE has been previously reported only for the brains of patients with HIV dementia; those having an apoE3/4 or E4/4 genotype have higher ceramide levels than patients with an apoE3/3 genotype (Cutler et al., 2004b). Moreover, apoE functions may not be reduced by apoE4 expression (White et al., 2001). We are currently examining sprouting, ceramides, and selected neurotrophic functions, in apoE4 transgenic mice.

\section{Conclusions}

The present findings suggest that the use of nontoxic inhibitors of ceramide production could be a valuable therapeutic strategy to promote compensatory sprouting in the compromised nervous system (e.g., Alzheimer's disease and related neurodegenerative disorders) and coincidentally reduce age- and ceramide-induced neuronal apoptosis.

\section{References}

Anderson R, Barnes JC, Bliss TV, Cain DP, Cambon K, Davies HA, Errington ML, Fellows LA, Gray RA, Hoh T, Stewart M, Large CH, Higgins GA (1998) Behavioural, physiological and morphological analysis of a line of apolipoprotein E knockout mouse. Neuroscience 85:93-110.

Arévalo JC, Chao MV (2005) Axonal growth: where neurotrophins meet Wnts. Curr Opin Cell Biol 17:112-115.

Bedlack RS, Strittmatter WJ, Morgenlander JC (2000) Apolipoprotein E and neuromuscular disease: a critical review of the literature. Arch Neurol 57:1561-1565.

Bergman E, Fundin BT, Ulfhake B (1999) Effects of aging and axotomy on the expression of neurotrophin receptors in primary sensory neurons. J Comp Neurol 410:368-386.

Bhattacharyya A, Watson FL, Pomeroy SL, Zhang YZ, Stiles CD, Segal RA (2002) High-resolution imaging demonstrates dynein-based vesicular transport of activated Trk receptors. J Neurobiol 51:302-312.

Blöchl A, Blöchl R (2007) A cell-biological model of p75NTR signaling. J Neurochem 102:289-305.

Chalfant CE, Kishikawa K, Mumby MC, Kamibayashi C, Bielawska A, Hannun YA (1999) Long chain ceramides activate protein phosphatase-1 and protein phosphatase-2A. Activation is stereospecific and regulated by phosphatidic acid. J Biol Chem 274:20313-20317.

Champagne D, Rochford J, Poirier J (2005) Effect of apolipoprotein E deficiency on reactive sprouting in the dentate gyrus of the hippocampus following entorhinal cortex lesion: role of the astroglial response. Exp Neurol 194:31-42.

Cheng H, Guan S, Han X (2006) Abundance of triacylglycerols in ganglia and their depletion in diabetic mice: Implications for the role of altered triacylglycerols in diabetic neuropathy. J Neurochem 97:1288-1300.

Cheng H, Jiang X, Han X (2007) Alterations in lipid homeostasis of mouse dorsal root ganglia induced by apolipoprotein E deficiency: a shotgun lipidomics study. J Neurochem 101:57-76.

Chiantia S, Kahya N, Ries J, Schwille P (2006) Effects of ceramide on liquidordered domains investigated by simultaneous AFM and FCS. Biophys J 90:4500-4508.

Chiantia S, Ries J, Chwastek G, Carrer D, Li Z, Bittman R, Schwille P (2008) Role of ceramide in membrane protein organization investigated by combined AFM and FCS. Biochim Biophys Acta 1778:1356-1364.

Crivello NA, Rosenberg IH, Dallal GE, Bielinski D, Joseph JA (2005) Agerelated changes in neutral sphingomyelin-specific phospholipase $\mathrm{C}$ activity in striatum, hippocampus, and frontal cortex: implication for sensitivity to stress and inflammation. Neurochem Int 47:573-579.

Crutcher KA (2002) Aging and neuronal plasticity: lessons from a model. Auton Neurosci 96:25-32.

Cutler RG, Kelly J, Storie K, Pedersen WA, Tammara A, Hatanpaa K, Troncoso JC, Mattson MP (2004a) Involvement of oxidative stress-induced abnormalities in ceramide and cholesterol metabolism in brain aging and Alzheimer's disease. Proc Natl Acad Sci U S A 101:2070-2075.

Cutler RG, Haughey NJ, Tammara A, McArthur JC, Nath A, Reid R, Vargas DL, Pardo CA, Mattson MP (2004b) Dysregulation of sphingolipid and sterol metabolism by ApoE4 in HIV dementia. Neurology 63:626-630.

de Chaves EI, Bussière M, Vance DE, Campenot RB, Vance JE (1997) Elevation of ceramide within distal neurites inhibits neurite growth in cultured rat sympathetic neurons. J Biol Chem 272:3028-3035.

de Chaves EP, Bussiere M, MacInnis B, Vance DE, Campenot RB, Vance JE (2001) Ceramide inhibits axonal growth and nerve growth factor uptake without compromising the viability of sympathetic neurons. J Biol Chem 276:36207-36214.

Desai K, Sullards MC, Allegood J, Wang E, Schmelz EM, Hartl M, Humpf HU, Liotta DC, Peng Q, Merrill AH Jr (2002) Fumonisin B1 and fumonisin $\mathrm{B} 1$ analogs as inhibitors of ceramide synthase and inducers of apoptosis. Biochim Biophys Acta 1585:188-192.

Desrosiers J, Bourbonnais D, Noreau L, Rochette A, Bravo G, Bourget A (2005) Participation after stroke compared to normal aging. J Rehabil Med 37:353-357.

Diamond J (1982) Modeling and competition in the nervous system: clues from the sensory innervation of skin. Curr Top Dev Biol 17:147-205.

Diamond J, Holmes M, Coughlin M (1992a) Endogenous NGF and nerve 
impulses regulate the collateral sprouting of sensory axons in the skin of the adult rat. J Neurosci 12:1454-1466.

Diamond J, Foerster A, Holmes M, Coughlin M (1992b) Sensory nerves in adult rats regenerate and restore sensory function to the skin independently of endogenous NGF. J Neurosci 12:1467-1476.

Fullerton SM, Strittmatter WJ, Matthew WD (1998) Peripheral sensory nerve defects in apolipoprotein E knockout mice. Exp Neurol 153:156-163.

Gage FH, Björklund A, Stenevi U (1983) Reinnervation of the partially deafferented hippocampus by compensatory collateral sprouting from spared cholinergic and noradrenergic afferents. Brain Res 268:27-37.

Gloster A, Diamond J (1992) Sympathetic nerves in adult rats regenerate normally and restore pilomotor function during an anti-NGF treatment that prevents their collateral sprouting. J Comp Neurol 326:363-374.

Han X (2002) Characterization and direct quantitation of ceramide molecular species from lipid extracts of biological samples by electrospray ionization tandem mass spectrometry. Anal Biochem 302:199-212.

Han X (2005) Lipid alterations in the earliest clinically recognizable stage of Alzheimer's disease: implication of the role of lipids in the pathogenesis of Alzheimer's disease. Curr Alzheimer Res 2:65-77.

Handelmann GE, Boyles JK, Weisgraber KH, Mahley RW, Pitas RE (1992) Effects of apolipoprotein E, beta-very low density lipoproteins, and cholesterol on the extension of neurites by rabbit dorsal root ganglion neurons in vitro. J Lipid Res 33:1677-1688.

Hannun YA, Obeid LM (2008) Principles of bioactive lipid signalling: lessons from sphingolipids. Nat Rev Mol Cell Biol 9:139-150.

Holtzman DM, Pitas RE, Kilbridge J, Nathan B, Mahley RW, Bu G, Schwartz AL (1995) Low density lipoprotein receptor-related protein mediates apolipoprotein E-dependent neurite outgrowth in a central nervous systemderived neuronal cell line. Proc Natl Acad Sci U S A 92:9480-9484.

Ignatius MJ, Gebicke-Härter PJ, Skene JH, Schilling JW, Weisgraber KH, Mahley RW, Shooter EM (1986) Expression of apolipoprotein E during nerve degeneration and regeneration. Proc Natl Acad Sci U S A 83:1125-1129.

Ignatius MJ, Shooter EM, Pitas RE, Mahley RW (1987) Lipoprotein uptake by neuronal growth cones in vitro. Science 236:959-962.

Johnson EM Jr, Taniuchi M, Clark HB, Springer JE, Koh S, Tayrien MW, Loy R (1987) Demonstration of the retrograde transport of nerve growth factor receptor in the peripheral and central nervous system. J Neurosci 7:923-929.

Johnston I, Johnston LJ (2006) Ceramide promotes restructuring of model raft membranes. Langmuir 22:11284-11289.

Johnston I, Johnston LJ (2008) Sphingomyelinase generation of ceramide promotes clustering of nanoscale domains in supported bilayer membranes. Biochim Biophys Acta 1778:185-197.

Kanje M, Skottner A, Lundborg G, Sjöberg J (1991) Does insulin-like growth factor (IGF-1) trigger the cell body reaction in the rat sciatic nerve? Brain Res 563:285-287.

Karchewski LA, Kim FA, Johnston J, McKnight RM, Verge VM (1999) Verge, Anatomical evidence supporting the potential for modulation by multiple neurotrophins in the majority of adult lumbar sensory neurons. J Comp Neurol 413:327-341.

Kitatani K, Idkowiak-Baldys J, Hannun YA (2007) Mechanism of inhibition of sequestration of protein kinase C alpha /beta II by ceramide: roles of ceramide-activated protein phosphatases and phosphorylation/dephosphorylation of protein kinase C alpha /beta II on threonine 638/641. J Biol Chem 282:20647-20656.

Kitatani K, Idkowiak-Baldys J, Hannun YA (2008) The sphingolipid salvage pathway in ceramide metabolism and signaling. Cell Signal 20:1010-1018.

Lahiri DK (2004) Apolipoprotein E as a target for developing new therapeutics for Alzheimer's disease based on studies from protein, RNA, and regulatory region of the gene. J Mol Neurosci 23:225-233.

Lourenssen S, Motro B, Bernstein A, Diamond J (2000) Defects in sensory nerve numbers and growth in mutant Kit and Steel mice. Neuroreport 11:1159-1165.

Mahley RW, Weisgraber KH, Huang Y (2006) Apolipoprotein E4: a causative factor and therapeutic target in neuropathology, including Alzheimer's disease. Proc Natl Acad Sci U S A 103:5644-5651.

Masliah E, Mallory M, Veinbergs I, Miller A, Samuel W (1996) Alterations in apolipoprotein $\mathrm{E}$ expression during aging and neurodegeneration. Prog Neurobiol 50:493-503.

Mearow KM, Kril Y, Diamond J (1993) Increased NGF mRNA expression in denervated rat skin. Neuroreport 4:351-354

Merrill AH Jr, van Echten G, Wang E, Sandhoff K (1993) Fumonisin B1 inhibits sphingosine (sphinganine) $N$-acyltransferase and de novo sphingolipid biosynthesis in cultured neurons in situ. J Biol Chem 268:27299-27306.

Murphy RA, Acheson A, Hodges R, Haskins J, Richards C, Reklow E, Chlumecky V, Barker PA, Alderson RF, Lindsay RM (1993) Immunological relationships of NGF, BDNF and NT3: recognition and functional inhibition by antibodies to NGF. J Neurosci 13:2853-2862.

Nathan BP, Bellosta S, Sanan DA, Weisgraber KH, Mahley RW, Pitas RE (1994) Differential effects of apolipoproteins E3 and E4 on neuronal growth in vitro. Science 264:850-852.

Pertens E, Urschel-Gysbers BA, Holmes M, Pal R, Foerster A, Kril Y, Diamond J (1999) Intraspinal and behavioral consequences of nerve growth factor-induced nociceptive sprouting and nerve growth factorinduced hyperalgesia compared in adult rats. J Comp Neurol 410:73-89.

Piomelli D, Astarita G, Rapaka R (2007) A neuroscientist's guide to lipidomics. Nat Rev Neurosci 8:743-754.

Poirier J (1994) Apolipoprotein E in animal models of CNS injury and in Alzheimer's disease. Trends Neurosci 17:525-530.

Poirier J, Davignon J, Bouthillier D, Kogan S, Bertrand P, Gauthier S (1993) Apolipoprotein E polymorphism and Alzheimer's disease. Lancet 342:697-699.

Popko B, Goodrum JF, Bouldin TW, Zhang SH, Maeda N (1993) Nerve regeneration occurs in the absence of apolipoprotein $\mathrm{E}$ in mice. J Neurochem 60:1155-1158.

Raivich G, Kreutzberg GW (1987) Expression of growth factor receptors in injured nervous tissue. I. Axotomy leads to a shift in the cellular distribution of specific beta-nerve growth factor binding in the injured and regenerating PNS. J Neurocytol 16:689-700.

Riebelin C, Futerman AH (2002) Ceramide in the regulation of neuronal development: two faces of a lipid. In: Ceramide signaling (Futerman $\mathrm{AH}$, ed), pp 101-111. New York: Kluwer Academic/Plenum.

Scheff SW, Bernardo LS, Cotman CW (1978) Decrease in adrenergic axon sprouting in the senescent rat. Science 202:775-778.

Skene JH, Shooter EM (1983) Denervated sheath cells secrete a new protein after nerve injury. Proc Natl Acad Sci U S A 80:4169-4173.

Strittmatter WJ, Saunders AM, Schmechel D, Pericak-Vance M, Enghild J, Salvesen GS, Roses AD (1993) Apolipoprotein E: high-avidity binding to beta-amyloid and increased frequency of type 4 allele in late-onset familial Alzheimer disease. Proc Natl Acad Sci U S A 90:1977-1981.

Szot P, White SS, Greenup JL, Leverenz JB, Peskind ER, Raskind MA (2006) Compensatory changes in the noradrenergic nervous system in the locus ceruleus and hippocampus of postmortem subjects with Alzheimer's disease and dementia with Lewy bodies. J Neurosci 26:467-478.

Toma JG, Rogers D, Senger DL, Campenot RB, Miller FD (1997) Spatial regulation of neuronal gene expression in response to nerve growth factor. Dev Biol 184:1-9.

Tsai SY, Yang LY, Wu CH, Chang SF, Hsu CY, Wei CP, Leu SJ, Liaw J, Lee YH, Tsai MD (2007) Injury-induced Janus kinase/protein kinase C-dependent phosphorylation of growth-associated protein 43 and signal transducer and activator of transcription 3 for neurite growth in dorsal root ganglion. J Neurosci Res 85:321-331.

Van der Zee CE, Rashid K, Le K, Moore KA, Stanisz J, Diamond J, Racine RJ, Fahnestock M (1995) Intraventricular administration of antibodies to nerve growth factor retards kindling and blocks mossy fiber sprouting in adult rats. J Neurosci 15: 5316-5323.

White F, Nicoll JA, Roses AD, Horsburgh K (2001) Impaired neuronal plasticity in transgenic mice expressing human apolipoprotein E4 compared to E3 in a model of entorhinal cortex lesion. Neurobiol Dis 8:611-625.

Yasargil GM, Macintyre L, Doucette R, Visheau B, Holmes M, Diamond J (1988) Axonal domains within shared touch domes in the rat: a comparison of their fate during conditions favoring collateral sprouting and following axonal regeneration. J Comp Neurol 270:301-312. 